kite. Another, or more probably the same, bird was seen at Tunstall and Snape a fortnight later. An immature purple heron was found injured beneath electric pylons at Herringfleet on September 9, and an ortolan, the first definite record for many years, was identified at Walberswick on September 1.

\section{Requirements for Poliomyelitis Vaccine}

Over the past four years, a number of World Health Organization Study Groups have met to consider requirements for biological substances which could be recommended for international adoption. Recommended requirements for inactivated poliomyelitis vaccine were published three years ago, but, since that time, live poliomyelitis vaccine, administered orally, has come into use for mass immunization programmes in many countries. It has therefore hecome necessary to formulate requirements for the oral vaccine. The recommendations of a recent report are restricted to the preparation of oral poliomyelitis vaccine in monkey kidney cultures, since, sofar, only vaccines prepared by this method have been extensively used in man (Technical Report Series. No. 237 : Requirements for Biological Substances. 7 : Requirements for Poliomyelitis Vaccine (Oral). Pp. 29. Geneva: World Health Organization; London: H.M.S.O., 1962. 1 Swiss franc; $1 s .9 d$.; $0 \cdot 30$ dollars). In drafting the requirements, the Study Group took into consideration the regulations and requirements already proposed by a number of national authorities, as well as data submitted by experts in the field, including the authors of three oral vaccines which have been tested in large-scale immunization campaigns in man.

\section{Ramsay Memorial Fellowships}

THE following Ramsay Memorial fellowships in chemistry for the year 1962-63 have been awarded: A Canadian fellowship to Dr. R. C. Thompson, University of Manchester; an Indian Fellowship to Dr. R.S. Thakur, University of Cambridge; a Netherlands Fellowship to Mr. A. Schuyff, Imperial College of Science and Technology, London; a New. Zealand Fellowship to Mr. D. T. Dixon, University of Reading; a Spanish Fellowship to Dr. D. Vazquez Martinez, University of Cambridge; a United States Fellowship to Mr. Jack H. Freed, University of Cambridge.

The following fellowships have been renewed for the same year to: Dr. H. Suginome (Japanese Fellowship), University of Cambridge; Mr. B. A. Grigor (New Zealand Fellowship), University of Leicester; Dr. F. Alonso Matthias (Spanish Fellowship), University of Cambridge.

\section{University News :}

London

Prof. R. A. L. BLack, Chamber of Mines professor of mining engineering in the University of the Witwatersrand, has been appointed to the chair of mining at the Imperial College of Science and Technology as from October 1, 1963.

Dr. J. F. Kirkaldy, reader in geology at Queen Mary College, has been appointed to the chair of geology tenable at that College. Dr. R. L. Bell, lecturer in metallurgy in the Imperial College of Science and Technology, has been appointed to the readership in science of materials tenable at Queen Mary College. Dr. P. M. Cohn, lecturer in the University of Manchester, has been appointed to the readership in pure mathematics tenable at Queen Mary College.
The following titles have been conferred: Professor, on Dr. A. M. Cook (pharmaceutics), in respect of his post at the School of Pharmacy; on Dr. B. Dawes (zoology-parasitology), in respect of his post at King's College. Reader, on Mr. B. B. Boycott (zoology), in respect of his post at University College; on Dr. R. E. Burge (biophysics), in respect of his post at King's College; on Mr. W. H. Gosney (mochanical engineering), in respect of his post at King's College.

\section{Announcements}

ThE Medical Research Council Clinical Chemotherapy Research Unit at the Western Infirmary, Glasgow, has been reconstituted as the Atheroma Research Unit under the direction of Dr. B. BronteStewart. The Unit will be primarily concerned with research on occlusive vascular disease.

A MeETrNa on "Scattering of Elastic Waves", arranged by the Materials and Testing Group of the Institute of Physics and the Physical Society, will be held on October 12. Further information can be obtained from the Institute of Physics and the Physical Society, 47 Belgrave Square, London, S.W.1.

THE annual Pittsburgh diffraction conference will be held at the Mellon Institute, Pittsburgh, during November 7-9. Subjects under discussion will include: instrumentation and techniques; structures; metals and alloys; defect lattices and/or radiation damage; X-ray and electron diffraction microscopy. Further information can be obtained from W. $\mathbf{H}$. Robinson, Carnegie Institute of Technology, Pittsburgh 13, Pennsylvania.

THE autumn meeting of the British Society for Parasitology will be held at the Zoological Society of London on October 19. Subjects under discussion will include: biochemical techniques; ionizing radiations and radioisotopes; in vitro cultivation and serological techniques; electron microscopy. Further information can be obtained from Dr. L. P. Joyner, Central Vetorinary Laboratory, Ministry of Agriculture, Fisheries and Food, New Haw, Weybridge, Surrey.

The thirty-sixth annual conference of Aslib will be held in Blackpool during October 2-4. Subjects under discussion will include: sharing skills; technical aid to developing countries; the foreign language barrier in science and technology; monitoring current technical information with the British technology index; linking research and design ; relations between a central information unit and sectional units; a multi-purpose, computer-integrated system for centralized information dissemination, storage and re. trieval. Further information can be obtained from Aslib, 3 Belgrave Square, London, S.W.1.

A conference on "The Epilepsies and Society", arranged by the Scottish Epilepsy Association, will be held at Dunblane Hydro during November 9-11. Subjects to be discussed will include: the challenge of the epilepsies in the welfare state; the scope and limitations of present-day treatment of the epilepsies; the management of the epilepsies in Germanyvocational guidance, settlement in employment; problems within the family; the social integration of persons with epilepsy; the employment of persons with epilepsy. Further information can be obtained from Mrs. Christina G. Kilgour, Scottish Epilepsy Association, 24 St. Vincent Place, Glasgow, C.1. 